\title{
The Clinical Implications of Cardiac Troponins
}

\section{Ali Abdul Jabbar*}

Department of Internal Medicine, Cardiology Division, Boonshoft School of Medicine, Wright State University, USA

With the advent of biomedical engineering and chemical testing, many diseases are now being diagnosed simply with a positive value of blood or serum test specific to that disease. Exceptions still exist in certain conditions, as the blood tests needs to be supported by the clinical assessment to explain these results; acute coronary syndrome is one of them [1].

In an ideal situation, a positive blood test to evaluate myocardial infarction in the setting of chest pain or critical illness would identify those who would benefit from early invasive testing and revascularization.

Cardiac biomarkers have been used to support the diagnosis of acute coronary syndromes. The newer tests have become the standard to detect myocardial ischemia and necrosis, while many of the older biomarkers have fallen out of favor in our clinical practice.

Troponin serves a regulatory function in the actin-myosin interaction, and plays an important role in the excitation-contraction coupling process of both the cardiac and skeletal muscles.

Antibody-based assays are directed against certain degradation sites for cardiac troponins to detect the presence of elevated troponin as an indication of myocardial cell injury but not the mechanism [2]. The gene encoding for the cardiac troponin is different from that of the skeletal myocyte, therefore it has a different amino acid sequence [3].

The impairment of myocardial flow changes the myocardial cell membrane integrity that leads to the release of the troponin into the blood stream. The major pool of the troponin is bound to the contractile elements of the myocytes. The rest is believed to reside freely in the cytosol [4].

A transient leakage of the cytosolic troponins due to disruption of the membrane integrity has different implications than a prolonged troponin leakage. The latter may indicate irreversible cellular damage [5].

The current dilemma is diagnosing acute coronary syndrome in critical care settings, where elevated troponin is an incidental finding that cannot be ignored, yet is not easily differentiated from a true underlying coronary artery disease.

Even in clinical settings where acute coronary syndromes are diagnosed clinically, the management of those without ST segment elevation electrocardiographic changes is constantly changing.

In critical care settings, troponin is not included as a marker of severe sepsis. Also the value of troponin as an independent risk factor for mortality has been negated.

In acute coronary syndromes, troponin elevations were associated with a high incidence of multi-vessel disease, complex lesions, visible thrombus and impairment of tissue perfusion on cardiac angiography. The latter was associated with a high mortality rate and adverse cardiac events at 6 months follow up [6-11].

The diagnosis of acute myocardial infarction (MI) should combine both an evidence of myocardial cell necrosis and a clinical setting consistent with acute myocardial ischemia [12].

Troponin elevation has prognostic implications, even if it is induced by exercise or from a structural heart disease without underlying obstructive coronary artery disease [13-16].

Reports are controversial in terms of the use of intravenous platelet inhibitory therapy [17-19], and who would benefit from early revascularization and invasive strategy $[20,21]$. However, it has been shown in previous reports that troponin elevation associated with adverse outcomes, and obstructive coronary artery disease, is more common with high troponin elevation [22].

To solve this dilemma, long-term follow up is recommended for patients with unexplained elevation of troponin in critical care settings. Also more prospective studies for those with ACS treated conservatively or with delayed interventions. TIMI risk score is still used in triaging patients with ACS

Our preliminary data suggests that troponin elevation is an independent risk factor for in-hospital mortality in a critical care setting. We also found that high troponin levels are more likely to be associated with a flow limiting coronary artery disease.

With regards to the TIMI risk score, it should be modified to include the degree of troponin elevation in order to improve the risk stratification of patients with elevated troponin levels. Early invasive strategies, or antiplatelet therapy, tailored to reduce troponin elevation and secure myocardial perfusion are worth pursuing.

\section{References}

1. Reichlin T, Hochholzer W, Bassetti S, Steuer S, Stelzig C, et al. (2009) Early diagnosis of myocardial infarction with sensitive cardiac troponin assays. $\mathrm{N}$ Engl J Med 361: 858-867.

2. Katruka A (2003) Antibody selection strategies in cardiac troponin assay Cardiac markers. (2ndedn), Totowa (NJ): Humana Press Inc., 173-186.

3. Christenson RH, Azzazy HM (1998) Biochemical markers of the acute coronary syndromes. Clin Chem 44: 1855-1864.

4. Jaffe AS (2001) Elevations in cardiac troponin measurements: false falsepositives: the real truth. Cardiovasc Toxicol 1: 87-92.

5. Katus HA, Schoeppenthau M, Tanzeem A, Bauer HG, Saggau W, et al (1991) Non-invasive assessment of perioperative myocardial cell damage by circulating cardiac troponin $\mathrm{T}$. Br Heart J 65: 259-264.

6. Matetzky S, Sharir T, Domingo M, Noc M, Chyu KY, et al. (2000) Elevated troponin I level on admission is associated with adverse outcome of primary angioplasty in acute myocardial infarction. Circulation 102: 1611-1616.

7. Lindahl B, Diderholm E, Lagerqvist B, Venge P, Wallentin L; FRISC II (Fas Revascularization during InStability in CAD) Investigators (2001) Mechanisms behind the prognostic value of troponin $\mathrm{T}$ in unstable coronary artery disease: a FRISC II substudy. J Am Coll Cardiol 38: 979-986.

*Corresponding author: Ali Abdul Jabbar, Department of Internal Medicine Cardiology Division, Boonshoft School of Medicine, Wright State University, USA, E-mail: alihaitham_dr@hotmail.com

Received April 15, 2013; Accepted May 18, 2013; Published May 20, 2013

Citation: Jabbar AA (2013) The Clinical Implications of Cardiac Troponins. Gen Med (Los Angel) 1: 108. doi:10.4172/2327-5146.1000108

Copyright: ( 2013 Jabbar AA. This is an open-access article distributed under the terms of the Creative Commons Attribution License, which permits unrestricted use, distribution, and reproduction in any medium, provided the original author and source are credited. 